\title{
Depression and mortality in a longitudinal study: 1952-2011
}

\author{
Stephen E. Gilman ScD, Ewa Sucha MSc, Mila Kingsbury PhD, Nicholas J. Horton ScD, Jane M. Murphy PhD, \\ Ian Colman PhD
}

Cite as: CMAJ 2017 October 23;189:E1304-10. doi: 10.1503/cmaj.170125

\begin{abstract}
BACKGROUND: Many studies have shown that depression increases mortality risk. We aimed to investigate the duration of time over which depression is associated with increased risk of mortality, secular trends in the association between depression and mortality, and sex differences in the association between depression and mortality.
\end{abstract}

METHODS: We conducted a cohort study of 3410 adults enrolled in 3 representative samples of a county in Atlantic Canada in $1952(n=1003), 1970(n=1203)$ or 1992 ( $n=1402$ ) (the Stirling County
Study). Depression was measured using a diagnostic algorithm based on the presence of depressed mood and associated symptoms, duration of more than 1 month, and substantial impairment. Vital status of participants through 2011 was determined using probabilistic linkages to the Canadian Mortality Database.

RESULTS: Depression was associated with a heightened risk of mortality among men during the 3 time periods of the study, with hazard ratios (HRs) of 2.90 (95\% confidence interval [Cl] 1.694.98) between 1952 and 1967, $1.97(\mathrm{Cl}$
1.34-2.89) between 1968 and 1990, and 1.52 ( $\mathrm{Cl} 1.09-2.13$ ) between 1991 and 2011. Elevated risk of mortality was noted among women only between 1990 and 2011 (HR $=1.51 ; \mathrm{Cl}=1.11-2.05)$.

INTERPRETATION: The association between depression and mortality persists over long periods of time and has emerged among women in recent decades, despite contemporaneous improvements in the treatment of depression and reduction of stigma associated with depression. Further research is needed to better understand the mechanisms involved. tudies have shown depression to be associated with shortened life expectancy. ${ }^{1}$ In Cuijpers and colleagues' metaanalysis of 293 studies, depression was associated with a $50 \%$ increased risk of mortality. ${ }^{2}$ There are 3 gaps in our understanding of the association between depression and mortality burden: the duration of time over which depression carries an increased risk of mortality, secular trends in the association between depression and mortality, and sex differences in the association between depression and mortality.

The duration of time over which depression increases mortality risk can provide insight into underlying mechanisms. Mortality risk over relatively short periods of time could be attributed to unnatural causes of death, including suicide and unintentional injuries - which are demonstrably elevated among individuals with depression., In contrast, mortality risk over longer periods of time may be more likely to result from chronic conditions associated with depression..$^{5-8}$ The question of duration is also important, from a clinical perspective: a history of depression is a strong predictor of later recurrence, and according to long-term follow-up studies, as many as one-third of individuals with depression will have a chronic form of the disorder. ${ }^{9-11}$
Any analysis of long-term elevations in mortality risk following depressive episodes should also consider secular trends, given broader changes in society; the past half-century has seen a reduction in the stigma associated with depression, an increased awareness of depression and the development of more tolerable and effective treatments for depression. ${ }^{12,13}$ Methodological differences across existing studies make it difficult to draw inferences regarding secular trends. ${ }^{14}$ Furthermore, despite higher rates of depression among women, ${ }^{15}$ it is unclear whether depression is associated with mortality among both sexes. ${ }^{7,16}$ Addressing these gaps requires populationbased data on depression and subsequent mortality over a long period.

Accordingly, we investigated depression and mortality in the 1952, 1970 and 1992 Stirling County Study samples. Previous reports from the Stirling County Study showed increased risk of mortality among participants with depression in the 1952 sample who were followed through $1968^{17-19}$ and through 1992, ${ }^{16}$ and increased mortality risk associated with depression among participants in the 1970 sample followed through $1992 .{ }^{20}$ Here, we 
extend these studies of the mortality experiences of 1952 and 1970 samples through 2011, as well as report for the first time on the mortality experience of the 1992 sample through 2011.

\section{Methods}

\section{Sample}

Three representative samples of adults were recruited from a county in Atlantic Canada with about 20000 residents, which has been given the pseudonym "Stirling": the first in 1952 ( $n=1003)$, the second in $1970(n=1203)$ and the third in $1992(n=1402) .{ }^{21}$ In 1952 , households from the county were sampled and an adult was randomly selected within each household, whereas in 1970 and 1992, individuals were randomly sampled from the full county census. Because the 3 samples were drawn independently, $5 \%(n=183)$ were selected for inclusion in more than 1 sample. The current investigation is based on 3410 Stirling County Study participants who provided data on depression status at one or more interviews.

\section{Measures}

Depression in the Stirling County Study was assessed using DPAX (DP for depression and AX for anxiety), a diagnostic algorithm similar to the Diagnostic and Statistical Manual of Mental Disorders, 3rd edition (DSM-III). ${ }^{22-25}$ A diagnosis of DPAX depression requires the presence of the essential features of depressed mood in addition to associated symptoms such as change in appetite, sleep and activity, of 1-month duration, and impairment in everyday functioning. DPAX compared favourably with several other types of diagnostic assessments, showing high values of sensitivity and specificity (i.e., usually $80 \%$ to $90 \%$ ). ${ }^{24-28}$

Vital status of Stirling County Study participants through Dec. 31,2011 , was determined using probabilistic linkages to the Canadian Mortality Database. The first linkage covered deaths that occurred through Dec. 31, 1992 (1047 deaths observed). ${ }^{16}$ The second is a newly completed linkage of the Stirling County Study 1992 survivors $(n=2586)$ to the mortality database that covers deaths that occurred through Dec. 31, 2011 (1014 deaths observed). The database linkage was implemented using the Generalized Iterative Record Linkage System, ${ }^{29,30}$ which generates probability ratios for each potential match between records in the study cohort and the Canadian Mortality Database based on participants' names, parents' names, date of birth, sex and postal code. Matches with high probability ratios were retained and low probability ratios discarded, and remaining matches were resolved manually.

\section{Analyses}

We fitted Cox proportional hazards models to the time-to-event outcome of date of death (for decedents), or censoring on Dec. 31 , 2011, yielding hazard ratios (HRs) and corresponding 95\% confidence intervals $(\mathrm{Cls}){ }^{31}$ These models used age as the time scale, thereby accounting for variation in age at entry into the sample. We considered 3 roughly equal time periods in the analyses: 1952 to 1967,1968 to 1990 , and 1991 to 2011. All analyses were conducted separately for men and women (with interactions involving sex tested in combined-sex analyses).
Calendar-time by depression interactions were tested to evaluate secular trends in the association between depression and mortality and assess the proportional hazards assumption. We also fitted models adjusted for the following factors measured upon participants' enrolment into the study, as these could potentially be explanatory factors for the association between depression and mortality: education (lower than 5th grade, 5th to 10 th grade, 11 th grade or higher), smoking (nonsmoker: smokes 1 to 19 cigarettes per day; smoker: smokes 20 or more cigarettes per day), alcohol abuse as observed by a primary care provider, and obesity as defined by a body mass index above 30 .

As follow-up data regarding depression status were available from those re-interviewed in 1970 or 1992, depression was modelled as time-varying, updating information from each subsequent interview in the calculation of hazard ratios. Depression status for participants alive but not re-interviewed at later waves was treated as time-invariant. In addition, we calculated life expectancies at age 25 for depressed and nondepressed men and women in each sample using abridged period life tables. ${ }^{32}$

\section{Ethics approval}

This study was approved by the Institutional Review Boards of the Massachusetts General Hospital and the Ottawa Health Science Network Research Ethics Board.

\section{Results}

The characteristics of participants in the Stirling County Study samples are provided in Table 1. Participation rates throughout the course of the Stirling County Study ranged between $79 \%$ and 91\%; Figure 1 depicts the number of participants enrolled and retained in each sample over time. The prevalence of current depression at each time point ranged from 6\% in the 1952 and 1970 samples to $6.5 \%$ in the 1992 sample, and was generally higher among women than men. The mean age at enrolment into the study was 49.7 years in 1952, 49.1 years in 1970 and 49.6 years in 1992. The number of deaths observed during the followup period was 925 in the 1952 sample, 854 in the 1970 sample and 444 in the 1992 sample (for the distribution of causes of death, see Appendix 1, available at www.cmaj.ca/lookup/suppl/ doi:10.1503/cmaj.170125/-/DC1).

On average, men and women with depression had shorter life expectancies in young adulthood than their nondepressed counterparts: a difference of 10 to 12 years in the 1952 sample, 7 years in the 1970 sample (men) and 7 to 18 years in the 1992 sample. In general, life expectancies at age 25 were lower for men than for women (Table 2). In the 3 combined samples, the median followup time was 19 years (interquartile range 16-36).

Results of survival analyses of the association between depression and mortality, by sex and calendar time, are presented in Table 3. The study's results were unchanged in sensitivity analyses that retained these individuals only in their firstenrolled sample.

Among men, the mortality risk associated with depression over the 3 calendar periods was most pronounced in the study's early years and diminished substantially over time. The period- 
specific hazard ratios were as follows: 2.90 (95\% Cl 1.69-4.98) between 1952 and 1967, 1.97 (95\% Cl 1.32-2.89) between 1968 and 1990, and 1.52 (95\% Cl 1.09-2.13) between 1991 and 2011.

Among women, there was little evidence for excess mortality risk among those with depression in the early years of the study, but a statistically significant one emerged over time. The periodspecific hazard ratios for women were 1.08 (95\% Cl 0.53-2.22) between 1952 and 1967, 1.37 (95\% Cl 0.90-2.07) between 1968 and 1991, and 1.51 (95\% Cl 1.11-2.05) between 1990 and 2011. By the end of the study period, the mortality risk associated with depression among both men and women converged to a similar degree of excess risk, which was not substantially altered after adjusting for education, smoking, obesity and alcohol use.

The results of survival analyses of the 3 Stirling County Study samples (1952, 1970 and 1992) are presented in Table 4. Where there was a significant association between depression and mortality, it was apparent only in the period encompassing the participants' first interview. Thus, for men in the 1952 sample, depression was associated with a 2.83 higher hazard of mortality (Cl 1.65-4.87) through 1967, but not in later periods. When depression status in the participants' most recent interview was considered, the attenuation of hazard ratios in later periods was less pronounced.

\section{Interpretation}

This study addresses the long-term association between depression and mortality - the duration of increased risk, secular trends over the past 6 decades and sex differences. The major finding from this study is that depression measured at any given point in time during the study carries an elevated risk of mortality that persists for as long as 2 decades. Our results show that a depressive episode confers an elevated risk of mortality that eventually decays over time unless there is a recurrent depressive episode, in which case the mortality risk associated with depression remains elevated. This decay was also reported in

Table 1: Characteristics of the Stirling County Study samples enrolled in 1952, 1970 and $1992(n=3410)$

\begin{tabular}{|c|c|c|c|c|c|c|c|c|c|}
\hline \multirow[b]{2}{*}{ Characteristic } & \multicolumn{3}{|c|}{ Participants enrolled in 1952} & \multicolumn{3}{|c|}{ Participants enrolled in 1970} & \multicolumn{3}{|c|}{ Participants enrolled in 1992} \\
\hline & $\begin{array}{c}\text { All } \\
n=1003\end{array}$ & $\begin{array}{l}\text { Women } \\
n=547\end{array}$ & $\begin{array}{c}\text { Men } \\
n=456\end{array}$ & $\begin{array}{c}\text { All } \\
n=1203\end{array}$ & $\begin{array}{l}\text { Women } \\
n=605\end{array}$ & $\begin{array}{c}\text { Men } \\
n=598\end{array}$ & $\begin{array}{c}\text { All } \\
n=1402\end{array}$ & $\begin{array}{l}\text { Women } \\
n=761\end{array}$ & $\begin{array}{c}\text { Men } \\
n=641\end{array}$ \\
\hline $\begin{array}{l}\text { No. of deaths through } \\
2011 \text { (\% of sample) }\end{array}$ & $925(92.2)$ & $489(89.4)$ & $436(95.6)$ & $854(71.0)$ & $394(65.1)$ & $460(76.9)$ & $444(31.7)$ & $226(29.7)$ & $218(34.0)$ \\
\hline $\begin{array}{l}\text { Age at enrolment, } \\
\text { mean } \pm \text { SD }\end{array}$ & $49.7 \pm 16.5$ & $48.9 \pm 17.1$ & $50.7 \pm 15.7$ & $49.1 \pm 17.5$ & $48.6 \pm 18.1$ & $49.7 \pm 16.8$ & $49.6 \pm 17.3$ & $50.0 \pm 17.7$ & $49.2 \pm 16.7$ \\
\hline \multicolumn{10}{|c|}{ Current depression status, no. (\%) } \\
\hline Current depression & $60(6.0)$ & $36(6.6)$ & $24(5.3)$ & $70(5.8)$ & $35(5.8)$ & $35(5.9)$ & $91(6.5)$ & $60(7.9)$ & $31(4.8)$ \\
\hline No depression & $943(94.0)$ & $511(93.4)$ & $432(94.7)$ & $1133(94.2)$ & $570(94.2)$ & $563(94.2)$ & $1311(93.5)$ & $701(92.1)$ & $610(95.2)$ \\
\hline \multicolumn{10}{|c|}{ Mortality rate per 1000 person-years among participants with and without current depression } \\
\hline Current depression & 38.1 & 29.8 & 61.6 & 32.7 & 27.7 & 39.5 & 28.6 & 23.9 & 39.4 \\
\hline No depression & 29.2 & 25.9 & 35.2 & 25.2 & 21.3 & 29.8 & 19.2 & 17.8 & 20.9 \\
\hline \multicolumn{10}{|l|}{ Education, no. (\%) } \\
\hline$<$ Grade 5 & $170(17.0)$ & $63(11.5)$ & $107(23.5)$ & $111(9.2)$ & $36(6.0)$ & $75(12.5)$ & $\begin{array}{l}47(3.4) \\
n=1400\end{array}$ & $11(1.5)$ & $\begin{array}{l}36(5.6) \\
n=639\end{array}$ \\
\hline Grade 5-10 & $655(65.3)$ & $360(65.8)$ & $295(64.7)$ & $835(69.4)$ & $408(67.4)$ & $427(71.4)$ & $\begin{array}{c}703(50.2) \\
n=1400\end{array}$ & $357(46.9)$ & $\begin{array}{c}346(54.2) \\
n=639\end{array}$ \\
\hline$\geq$ Grade 11 & $178(17.8)$ & $124(22.7)$ & $54(11.8)$ & $257(21.4)$ & $161(26.6)$ & $96(16.1)$ & $\begin{array}{c}650(46.4) \\
n=1400\end{array}$ & $393(51.6)$ & $\begin{array}{c}257(40.2) \\
n=639\end{array}$ \\
\hline \multicolumn{10}{|c|}{ Cigarettes smoked per day, no. (\%) } \\
\hline None & $505(50.4)$ & $412(75.3)$ & $93(20.4)$ & $577(48.0)$ & $399(66.0)$ & $178(29.8)$ & $\begin{array}{c}921(66.5) \\
n=1385\end{array}$ & $\begin{array}{c}546(72.4) \\
n=754\end{array}$ & $\begin{array}{c}375(59.4) \\
n=631\end{array}$ \\
\hline$>20$ & $103(10.3)$ & $8(1.5)$ & $95(20.8)$ & $147(12.2)$ & $24(4.0)$ & $123(20.6)$ & $\begin{array}{c}226(16.3) \\
n=1385\end{array}$ & $\begin{array}{c}86(11.4) \\
n=754\end{array}$ & $\begin{array}{c}140(22.2) \\
n=631\end{array}$ \\
\hline$<20$ & $395(39.4)$ & $127(23.2)$ & $268(58.8)$ & $479(39.8)$ & $182(30.1)$ & $297(49.7)$ & $\begin{array}{c}238(17.2) \\
n=1385\end{array}$ & $\begin{array}{c}122(16.2) \\
n=754\end{array}$ & $\begin{array}{c}116(18.4) \\
n=631\end{array}$ \\
\hline Alcohol abuse, no. (\%) & $\begin{array}{l}39(4.1) \\
n=953\end{array}$ & $\begin{array}{l}3(0.6) \\
n=523\end{array}$ & $\begin{array}{l}36(8.4) \\
n=430\end{array}$ & $\begin{array}{l}69(6.4) \\
n=1080\end{array}$ & $\begin{array}{l}8(1.5) \\
n=551\end{array}$ & $\begin{array}{c}61(11.5) \\
n=529\end{array}$ & $\begin{array}{c}97(7.0) \\
n=1395\end{array}$ & $\begin{array}{l}16(2.1) \\
n=757\end{array}$ & $\begin{array}{c}81(12.7) \\
n=638\end{array}$ \\
\hline Obesity, no. (\%) & $\begin{array}{l}68(7.1) \\
n=953\end{array}$ & $\begin{array}{l}51(9.8) \\
n=523\end{array}$ & $\begin{array}{l}17(4.0) \\
n=430\end{array}$ & $\begin{array}{c}149(12.4) \\
n=1201\end{array}$ & $\begin{array}{c}92(15.2) \\
n=604\end{array}$ & $\begin{array}{l}57(9.6) \\
n=597\end{array}$ & $\begin{array}{c}314(22.5) \\
n=1396\end{array}$ & $\begin{array}{c}176(23.2) \\
n=758\end{array}$ & $\begin{array}{c}138(21.6) \\
n=638\end{array}$ \\
\hline
\end{tabular}

Note: $\mathrm{SD}=$ standard deviation 
Cuijpers and colleagues' meta-analysis. ${ }^{2}$ Within an individual, the effect of a depressive episode on survival may decay over time unless depression recurs.

In addition, there appears to have been a secular trend characterized by a reduced impact of depression during the course of the last 6 decades, which has not been directly examined in previous studies. This secular trend may reflect increasing awareness of mental illness, decreasing stigma and improved treatment of depression in more recent calendar periods.

We also observed a significant secular trend by sex in the association between depression and mortality. Whereas the mortality risk associated with depression was observed primarily among men in the early decades of the follow-up period, an increased mortality risk among depressed women emerged in the later decades of the study, beginning in the 1990s. In the last calendar period analyzed (1991-2011), the mortality risk associated with depression was the same for both sexes (HR 1.5). Previous studies generally found a higher mortality burden of depression among men than women. ${ }^{33,34}$ However, these studies followed single cohorts of individuals and thus could not assess secular trends in gender differences in mortality associated with depression.

The long-term mortality burden of depression may reflect the cumulative impact of health-related behaviours over time that are associated with chronic conditions to which most deaths are attributable. Depression is associated with poor quality of diet, infrequent exercise, smoking and excessive alcohol use..$^{36-38}$ It has also been suggested that depression may be associated with physiologic changes to the cardiovascular system that directly affect risk of cardiovascular mortality. ${ }^{39}$

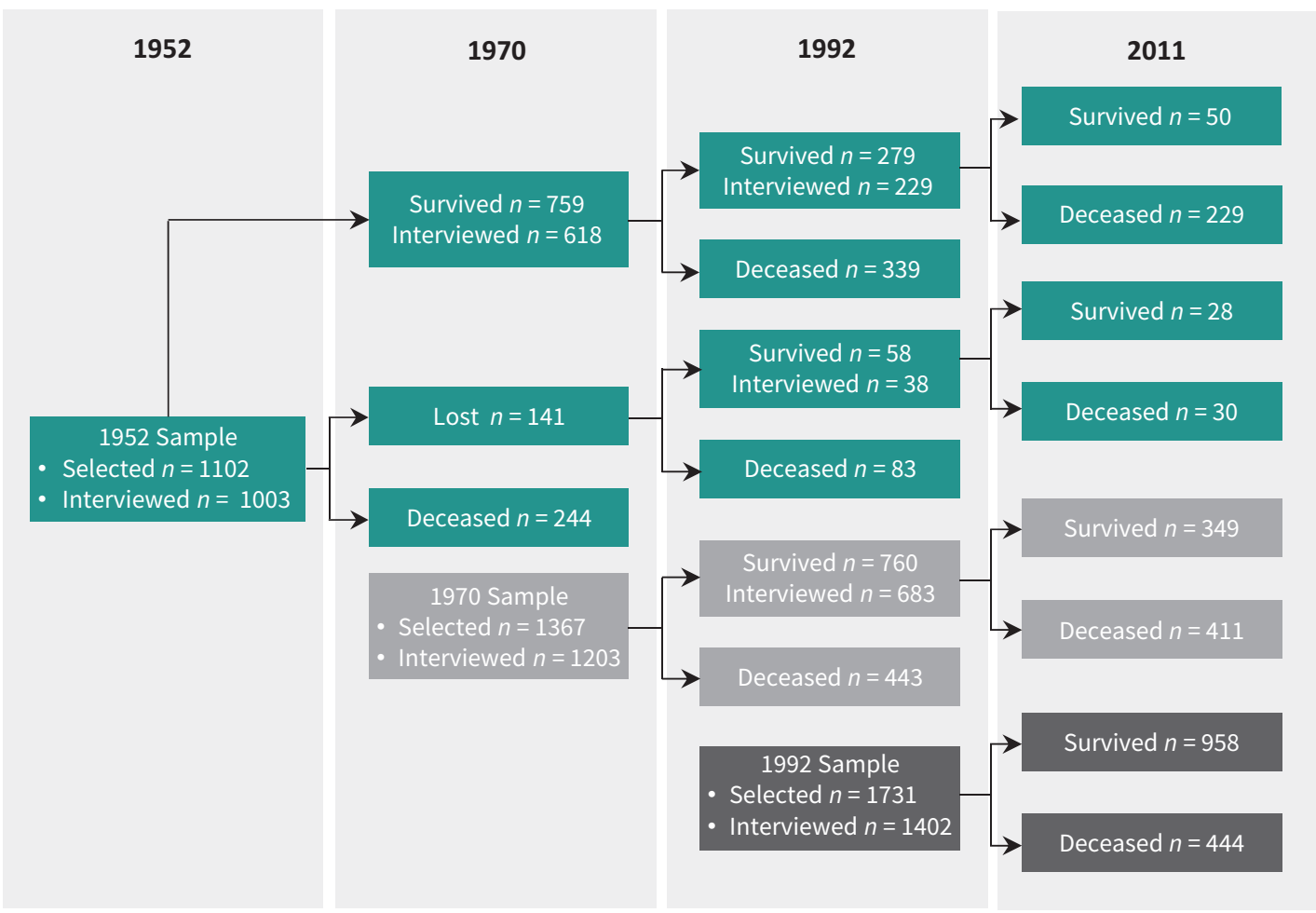

Figure 1: Flow diagram of participants through the 3 Stirling County Study samples. The diagram depicts the number of participants selected for each sample (1952, 1970 or 1992), interviewed following selection, re-interviewed at later phases of the study, and survived through the study period that ended Dec. 31, 2011.

Table 2: Average remaining years of life expectancy at age 25 by sex and depression status for the 1952, 1970 and 1992 Stirling County Study samples

Women, yr (95\% Cl)

\section{Sample}

1952

1970

1992

\section{Depressed}

$47.2(27.8-66.7)$

$59(53.7-64.3)$

37.8 (18.3-57.3)
Not depressed

$56.3(54.5-58.2)$

$55.8(54.1-57.4)$

$56.4(52.9-60)$
Men, $\operatorname{yr}(95 \% \mathrm{CI})$

\begin{tabular}{|c|} 
Depressed \\
\hline $38.6(24.2-53)$ \\
\hline $42.9(34.8-51)$ \\
\hline $43(35.6-50.5)$
\end{tabular}

Not depressed

$50.8(49.2-52.4)$

$49.3(47.2-51.3)$

$50.6(48.6-52.7)$

Note: $\mathrm{Cl}=$ confidence interval 
Changes in health-related behaviours associated with depression may also have contributed to the sex differences observed. For example, smoking and alcohol abuse have been, historically, more prevalent among men. ${ }^{40}$ Although smoking rates have decreased in the general population, the sex difference in smoking has decreased by virtue of an increase among women. Contemporaneously, smoking has become more strongly linked with depression. ${ }^{41}$ That said, adjustment for smoking and alcohol abuse in the present study did not explain the elevated mortality risk among individuals with depression.

Secular trends observed in the Stirling County Study concerning the emergence of an increased mortality risk associated with depression among women correspond to a time period of major changes in women's employment and economic circumstances. By 1990, the gap between women's and men's participation in the labour force that had existed at the beginning of the study period had narrowed considerably. ${ }^{42}$ The changing roles of women in and outside of the home may have been a contributor to the increasing mortality burden of depression among working-age women, as they carried the responsibility for multiple roles.

Thus, despite reductions in stigma associated with depression and the wider availability and effectiveness of depression treatments, the association between depression and mortality has persisted over time - and appears to have increased among women. Many depressed persons do not receive treatment for their condition. Insofar as treatment is received, it is provided mainly by general physicians. This suggests that providers of primary care give close attention to signs of mood disturbance among their patients and be particularly vigilant for recurrent depressive episodes.

Table 3: Survival analyses of the mortality risk associated with current depression among men and women in the Stirling County Study by time period, 1952-2011 $(n=3410)^{\star}$

\begin{tabular}{|c|c|c|c|c|c|c|}
\hline \multirow[b]{2}{*}{ Survival model } & \multicolumn{3}{|c|}{ Men, HR (95\% CI) } & \multicolumn{3}{|c|}{ Women, HR (95\% CI) } \\
\hline & $1952-1967$ & 1968-1990 & 1991-2011 & $1952-1967$ & $1968-1990$ & 1991-2011 \\
\hline $\begin{array}{l}\text { Mortality risk associated with depression at the most recent } \\
\text { interview } \dagger, \ddagger\end{array}$ & $\begin{array}{c}2.90 \\
(1.69-4.98)\end{array}$ & $\begin{array}{c}1.97 \\
(1.34-2.89)\end{array}$ & $\begin{array}{c}1.52 \\
(1.09-2.13)\end{array}$ & $\begin{array}{c}1.08 \\
(0.53-2.22)\end{array}$ & $\begin{array}{c}1.37 \\
(0.90-2.07)\end{array}$ & $\begin{array}{c}1.51 \\
(1.11-2.05)\end{array}$ \\
\hline $\begin{array}{l}\text { Mortality risk adjusted for education, smoking, alcohol abuse } \\
\text { and obesity }\end{array}$ & $\begin{array}{c}2.84 \\
(1.59-5.07)\end{array}$ & $\begin{array}{c}2.00 \\
(1.34-2.98)\end{array}$ & $\begin{array}{c}1.32 \\
(0.93-1.87)\end{array}$ & $\begin{array}{c}1.10 \\
(0.53-2.26)\end{array}$ & $\begin{array}{c}1.33 \\
(0.86-2.05)\end{array}$ & $\begin{array}{c}1.62 \\
(1.19-2.21)\end{array}$ \\
\hline No. of deaths & 122 & 440 & 476 & 111 & 347 & 569 \\
\hline Person-years & 7093.9 & 15360.0 & 13994.3 & 9848.8 & 18858.0 & 18466.9 \\
\hline \multicolumn{7}{|c|}{$\begin{array}{l}\text { Note: } \mathrm{Cl}=\text { confidence interval, } \mathrm{HR}=\text { hazard ratio. } \\
\text { *These analyses combine person-time contributed from all } 3 \text { Stirling County Study samples together, thereby allowing for robust estimation of secular trends. Using data from the } \\
\text { follow-up interviews allowed us to shorten considerably the time from last assessment of depression status: } 64 \% \text { of the combined sample had their depression status assessed less } \\
\text { than } 20 \text { years ago compared with } 21 \% \text { when only depression at baseline was considered. } \\
\text { †Test of the } 3 \text {-way interactions between gender }{ }^{\star} \text { calendar period }{ }^{\star} \text { depression status at recent interview: } \chi^{2}=3.81, \mathrm{df}=2, p=0.2 \text {. } \\
\ddagger \text { Test of interaction between depression at the most recent interview and sample: } \chi^{2}=1.26, \mathrm{df}=2, p=0.5 \text { for } \text { men, and } \chi^{2}=1.23, \mathrm{df}=2, p=0.5 \mathrm{for} \text { women. }\end{array}$} \\
\hline
\end{tabular}

Table 4: Survival analyses of the mortality risk associated with depression status among men and women in the Stirling County Study by sample, 1952-2011 $(n=3410)$

\begin{tabular}{|c|c|c|c|c|c|c|}
\hline \multirow[b]{2}{*}{ Survival model } & \multicolumn{3}{|c|}{ Men, HR $(95 \% \mathrm{Cl})$} & \multicolumn{3}{|c|}{ Women, HR (95\% Cl) } \\
\hline & 1952-1967 & 1968-1990 & 1991-2011 & 1952-1967 & 1968-1990 & 1991-2011 \\
\hline \multicolumn{7}{|c|}{ Depression status at the first interview* } \\
\hline 1952 sample & $2.83(1.65-4.87)$ & $0.92(0.41-2.08)$ & $1.14(0.36-3.62)$ & $1.07(0.52-2.20)$ & $1.06(0.63-1.77)$ & $0.76(0.39-1.49)$ \\
\hline 1970 sample & & $2.27(1.41-3.64)$ & $1.07(0.56-2.01)$ & & $0.99(0.54-1.83)$ & $1.03(0.62-1.71)$ \\
\hline 1992 sample & & & $1.87(1.12-3.12)$ & & & $1.76(1.13-2.74)$ \\
\hline \multicolumn{7}{|c|}{ Depression status at the most recent interview $\dagger$} \\
\hline 1952 sample & $2.84(1.65-4.89)$ & $1.75(0.92-3.10)$ & $1.88(0.95-3.73)$ & $1.08(0.52-2.21)$ & $1.97(1.14-3.40)$ & $1.03(0.55-1.96)$ \\
\hline 1970 sample & & $2.27(1.42-3.64)$ & $1.41(0.87-2.29)$ & & $0.99(0.54-1.83)$ & $1.69(1.05-2.70)$ \\
\hline 1992 sample & & & $1.87(1.12-3.12)$ & & & $1.76(1.13-2.75)$ \\
\hline
\end{tabular}

Note: $\mathrm{Cl}=$ confidence interval, $\mathrm{HR}=$ hazard ratio

*Test of gender ${ }^{*}$ calendar period ${ }^{*}$ depression (at first interview) interaction in the 1952 sample: $\chi^{2}=2.75, \mathrm{df}=2, p=0.3 ; 1970$ sample: $\chi^{2}=1.91, \mathrm{df}=1, p=0.2 ;$ and 1992 sample: $\chi^{2}=0.03$, $\mathrm{df}=1, p=0.9$.

†Test of gender ${ }^{*}$ calendar period ${ }^{*}$ depression (at recent interview) in the 1952 sample: $\left.\chi^{2}=3.16, \mathrm{df}=2, p=0.2\right) ; 1970$ sample: $\chi^{2}=3.68, \mathrm{df}=1, p=0.05$ ); and 1992 sample: $\chi^{2}=0.03, \mathrm{df}=1$, $p=0.9$. 


\section{Limitations}

Unobserved heterogeneity tends to produce estimated hazard functions that decline with time even when the true hazard remains constant. ${ }^{37}$ Thus, hazard ratios from survival models with long follow-up times are likely to be biased downward. Survivor bias in the later years of follow-up can also mask underlying associations between depression and mortality. Our estimates of the mortality burden of depression may therefore be conservative. This study was not able to control for some factors that are potentially relevant in the association between depression and mortality, such as cognitive decline (which was measured only among older adults in the study), chronic conditions and physical disability. Although participant retention exceeded $80 \%$ throughout the course of the study, misclassification of depression status in 1970 and 1992 of participants enrolled earlier in the study but not reinterviewed could have introduced bias. As a result, our analyses may overstate the decay in mortality risk associated with depression over long periods of time. Finally, the relatively long time between interviews did not allow us to track the effect of depression on mortality in greater detail - for example, yearly. More frequent interviews would increase the accuracy of the obtained hazard ratios and evaluate more precisely the duration over which the effect of depression on mortality persists.

Finally, incompleteness of the mortality linkage conducted by Statistics Canada could have biased the results. Study participants who died but did not have a death certificate recorded in a provincial registry were therefore analyzed as alive. However, the projected number of deaths through 2011 generated by applying the provincial mortality rates to the age and sex distribution of the sample in $1993(n=988)$ was very close to the number of participants linked to a death certificate $(n=1014)$.

\section{Conclusion}

The association between depression and mortality persists over long periods of time. The association was strongest for current depression, which tended to weaken within an individual over time unless there was a recurrent episode. The important implication of this finding, which needs to be pursued further, is whether remission from depression (either spontaneously or due to treatment) can reverse the elevated risk of mortality otherwise associated with depression.

\section{References}

1. Walker ER, McGee RE, Druss BG. Mortality in mental disorders and global disease burden implications: a systematic review and meta-analysis. JAMA Psychiatry 2015;72:334-41.

2. Cuijpers $P$, Vogelzangs $\mathrm{N}$, Twisk J, et al. Comprehensive meta-analysis of excess mortality in depression in the general community versus patients with specific illnesses. Am J Psychiatry 2014;171:453-62.

3. Sun W, Schooling CM, Chan WM, et al. The association between depressive symptoms and mortality among Chinese elderly: a Hong Kong cohort study. $J$ Gerontol A Biol Sci Med Sci 2011;66:459-66.

4. Zivin K, Yosef M, Miller EM, et al. Associations between depression and all-cause and cause-specific risk of death: a retrospective cohort study in the Veterans Health Administration. J Psychosom Res 2015;78:324-31.

5. Glymour MM, Maselko J, Gilman SE, et al. Depressive symptoms predict incident stroke independently of memory impairments. Neurology 2010;75:2063-70.
6. Dowlati Y, Herrmann N, Swardfager W, et al. A meta-analysis of cytokines in major depression. Biol Psychiatry 2010;67:446-57.

7. Kozela M, Bobak M, Besala A, et al. The association of depressive symptoms with cardiovascular and all-cause mortality in Central and Eastern Europe: prospective results of the HAPIEE study. Eur J Prev Cardiol 2016;23:1839-47.

8. Teng PR, Yeh CJ, Lee MC, et al. Change in depressive status and mortality in elderly persons: results of a national longitudinal study. Arch Gerontol Geriatr 2013;56:244-9.

9. Eaton WW, Shao H, Nestadt G, et al. Population-based study of first onset and chronicity in major depressive disorder [published erratum in Arch Gen Psychiatry 2008;65:838]. Arch Gen Psychiatry 2008;65:513-20.

10. Murphy JM, Olivier DC, Sobol AM, et al. Diagnosis and outcome: depression and anxiety in a general population. Psychol Med 1986;16:117-26.

11. Patten SB. Recurrence risk in major depression. Depress Anxiety 2013;30:1-4.

12. Mulrow CD, Williams JW Jr, Chiquette E, et al. Efficacy of newer medications for treating depression in primary care patients. Am J Med 2000;108:54-64.

13. Stuart H. Fighting the stigma caused by mental disorders: past perspectives, present activities, and future directions. World Psychiatry 2008;7:185-8.

14. Wulsin LR, Vaillant GE, Wells VE. A systematic review of the mortality of depression. Psychosom Med 1999;61:6-17.

15. Bromet E, Andrade LH, Hwang I, et al. Cross-national epidemiology of DSM-IV major depressive episode. BMC Med 2011;9:90.

16. Murphy JM, Burke JD Jr, Monson RR, et al. Mortality associated with depression: a forty-year perspective from the Stirling County Study. Soc Psychiatry Psychiatr Epidemiol 2008;43:594-601.

17. Murphy JM, Monson RR, Olivier DC, et al. Affective disorders and mortality. A general population study. Arch Gen Psychiatry 1987;44:473-80.

18. Murphy JM, Monson RR, Olivier DC, et al. Mortality risk and psychiatric disorders. Results of a general physician survey. Soc Psychiatry Psychiatr Epidemiol 1989; 24:134-42.

19. Horton NJ, Laird NM, Murphy JM, et al. Multiple informants: mortality associated with psychiatric disorders in the Stirling County Study. Am J Epidemiol 2001; 154:649-56.

20. Murphy JM, Gilman SE, Lesage A, et al. Time trends in mortality associated with depression: findings from the Stirling County Study. Can J Psychiatry 2010;55:776-83.

21. Murphy JM, Laird NM, Monson RR, et al. A 40-year perspective on the prevalence of depression: the Stirling County Study. Arch Gen Psychiatry 2000;57:209-15.

22. Diagnostic and statistical manual of mental disorders: DSM-III. 3rd ed. Washington: American Psychiatric Association; 1980.

23. Murphy JM. Continuities in community-based psychiatric epidemiology. Arch Gen Psychiatry 1980;37:1215-23.

24. Murphy JM, Neff RK, Sobol AM, et al. Computer diagnosis of depression and anxiety: the Stirling County Study. Psychol Med 1985;15:99-112.

25. Murphy JM, Monson RR, Laird NM, et al. Identifying depression and anxiety in a 40-year epidemiologic investigation: the Stirling County Study. Int J Methods Psychiatr Res 1998;7:89-109.

26. Leighton AH, Leighton DC, Danley RA. Validity in mental health surveys. Can Psychiatr Assoc J 1966;11:167-78.

27. Murphy JM, Berwick DM, Weinstein MC, et al. Performance of screening and diagnostic tests. Application of receiver operating characteristic analysis. Arch Gen Psychiatry 1987;44:550-5.

28. Murphy JM, Horton NJ, Laird NM, et al. Anxiety and depression: a 40-year perspective on relationships regarding prevalence, distribution, and comorbidity. Acta Psychiatr Scand 2004;109:355-75.

29. Howe GR, Lindsay J. A generalized iterative record linkage computer system for use in medical follow-up studies. Comput Biomed Res 1981;14:327-40.

30. Smith ME, Newcombe HB. Use of the Canadian Mortality Data Base for epidemiological follow-up. Can J Public Health 1982;73:39-46.

31. Cox DR. Regression models and life-tables. J R Stat Soc B 1972;34:187-220.

32. Chiang CL. The life table and its applications. Original ed. Malabar (FL): Krieger; 1984. 
33. Cuijpers $\mathrm{P}$, Vogelzangs $\mathrm{N}$, Twisk J, et al. Is excess mortality higher in depressed men than in depressed women? A meta-analytic comparison. J Affect Disord 2014;161:47-54.

34. Mattisson C, Bogren M, Bradvik L, et al. Mortality of subjects with mood disorders in the Lundby community cohort: a follow-up over 50 years. J Affect Disord 2015;178:98-106.

35. Heckman JJ, Singer B; Social Science Research Council. Longitudinal analysis of labor market data. Cambridge (UK), New York: Cambridge University Press; 1985.

36. Appelhans BM, Whited MC, Schneider KL, et al. Depression severity, diet quality, and physical activity in women with obesity and depression. J Acad Nutr Diet 2012;112:693-8.

37. Kingsbury M, Dupuis G, Jacka F, et al. Associations between fruit and vegetable consumption and depressive symptoms: evidence from a national Canadian longitudinal survey. J Epidemiol Community Health 2016;70:155-61.
38. Roshanaei-Moghaddam B, Katon WJ, Russo J. The longitudinal effects of depression on physical activity. Gen Hosp Psychiatry 2009;31:306-15.

39. Larson SL, Owens PL, Ford D, et al. Depressive disorder, dysthymia, and risk of stroke: thirteen-year follow-up from the Baltimore epidemiologic catchment area study. Stroke 2001;32:1979-83.

40. Peters SA, Huxley RR, Woodward M. Do smoking habits differ between women and men in contemporary Western populations? Evidence from half a million people in the UK Biobank study. BMJ Open 2014;4:e005663.

41. Murphy JM, Horton NJ, Monson RR, et al. Cigarette smoking in relation to depression: historical trends from the Stirling County Study. Am J Psychiatry 2003;160:1663-9.

42. Fullerton HN. Labor force participation: 75 years of change, 1950-98 and 19982005. Mon Labor Rev 1999;122:3-12.
Competing interests: Ian Colman, Jane Murphy and Mila Kingsbury report grants from the Canadian Institutes of Health Research, during the conduct of the study. Jane Murphy reports a grant from the National Institute of Mental Health, during the conduct of the study. No other competing interests were declared.

This article has been peer reviewed.

Affiliations: Health Behavior Branch, Division of Intramural Population Health Research (Gilman), Eunice Kennedy Shriver National Institute of Child Health and Human Development, Bethesda, Md.; Department of Mental Health (Gilman), Johns Hopkins Bloomberg School of Public Health, Baltimore, Md.; Department of Mathematics and Statistics (Sucha), and School of Epidemiology and Public Health (Sucha, Kingsbury), University of Ottawa, Ottawa, Ont.; Department of Mathematics and Statistics (Horton), Amherst College, Amherst, Mass.; Department of Psychiatry (Murphy), Massachusetts General Hospital and Harvard
Medical School; Department of Epidemiology (Murphy), Harvard TH Chan School of Public Health, Boston, Mass.; Department of Psychiatry (Murphy), Dalhousie University Faculty of Medicine, Halifax, NS; School of Epidemiology, Public Health \& Preventive Medicine (Colman), University of Ottawa, Ottawa, Ont.

Contributors: Jane Murphy, Principal Investigator of the Stirling County Study, with Stephen Gilman and Ian Colman, conceived and designed the current study. Ewa Sucha performed the statistical analysis. All of the authors contributed to the drafting of the manuscript, revised it critically for intellectual content, approved the final version to be published, and agree to be accountable for all aspects of the work.

Funding: This work was supported by the Canadian Institutes of Health Research (grant no. 126099), National Institute of Mental Health grant RO1-MH39576, and the Intramural Research Program of the Eunice Kennedy
Shriver National Institute of Child Health and Human Development. This research was undertaken, in part, thanks to support from the Canada Research Chairs program for Ian Colman.

Acknowledgements: The Stirling County Study was initiated by the late Alexander Leighton in 1948 and has been directed by Jane Murphy since 1975. We appreciate the contributions of Richard Trudeau, Yves Decady and Craig Grimes at Statistics Canada for their work in carrying out the linkage to the Canadian Mortality Database, and of the Provincial Registrars who made the information available to us. In addition, we acknowledge with sadness the passing of Arthur M. Sobol, long-term programmer with the Stirling County Study, who died on Sept. 14, 2016 after contributing to this paper.

Accepted: July 5, 2017

Correspondence to: Stephen Gilman, stephen.gilman@nih.gov 